\title{
PENERAPAN METODE MEASUREMENT SYSTEM ANALYSIS GAGE $R \& R$ PADA PENGUKURAN PRODUK BASE PLATE MAGAZINE
}

\author{
Albertus Laurensius Setyabudhi ${ }^{1 *}$, Okta Veza ${ }^{2}$, Delia Meldra ${ }^{3}$, Nandar Cundara Abdurahman ${ }^{4}$, dan \\ Muhammad Rizki Reza Saputra ${ }^{5}$
}

\author{
1,3,4,5Program Studi Teknik Industri, Universitas Ibnu Sina, Jl. Teuku Umar, Lubuk Baja \\ ${ }^{2}$ Program Studi Teknik Informatika, Universitas Ibnu Sina, Jl. Teuku Umar, Lubuk Baja \\ PT APT, Kawasan Lytech Home II Blok A, No. 10, Sadai, Bengkong \\ *email: abyan@uis.ac.id
}

\begin{abstract}
In the current era of globalization, the perceived quality competition globally is manufacturing. Manufacture industry competition makes companies must concentrate on product quality. and the quality of the factors affecting the product is wrong, such as human resources, tools / machines, and the environment can also cause product quality. And one of the companies engaged in the manufacturing industry, namely PT. APT has a problem with the quality measurement of the dimensions of size on one of the products made, where the product can't be accepted by the customer and declared reject on all the number of products sent. There are indications of $Q C$ checking errors within the company so that reject products are accepted as acceptable. The purpose of this research is to find out what are the main causes of goods declared acceptable internally within the company and when it arrives at the customer is declared reject. And find solutions to how such mistakes do not happen again. To solve this problem, this study uses the MSA (Measurement System Analysis Gage R\&R) method which has the advantage of knowing the cause of quality problems in detail whether from the people, tools, or supporting factors in a measurement. So that mistakes that occur before do not happen again and the company can run more effectively, efficiently and consistently in measuring and checking.
\end{abstract}

Keywords: Quality, Measurement, Gage R\&R

\section{Pendahuluan}

Pada era globalisasi sekarang ini terutama menyikapi perkembangan ilmu pengetahuan teknologi dan pola pikir manusia yang semakin maju, mendorong setiap manusia untuk dapat berkembang dan menjadikan perkembangan yang ada sebagai usaha untuk lebih meningkatkan kualitas masing-masing, Salah satu persaingan kualitas yang dirasakan secara global adalah manufaktur. Persaingan industri membuat perusahaan harus konsentrasi terhadap kualitas produk. maupun kualitas faktor yang memperngaruhi produk tersebut salah seperti sumber daya manusianya, alat/mesin, serta lingkungan juga bisa menyebabkan kualitas produk. Dalam penelitian ini dilakukan di PT APT. Perusahaan ini sangat memeperhatikan kualitas produk yang dihasikan khususnya pada pengecekan produk base plate magazine. Berdasarkan permintaan customer maksimal kerataan (flatness) yang diperbolehkan adalah $0.030 \mathrm{~mm}$, namun yang hasil yang didapatkan dari pihak customer berdasarkan 20 sampling yang diambil rata-rata dimensi yang didapat adalah 0.040-0.050 $\mathrm{mm}$, karena dari sampel yang telah diambil oleh customer dinyatakan outspec maka semua unit yang sudah dikirim pada bulan januari 2019 dikembalikan semuanya. Jumlah unit yang dikembalikan sebesar 120 unit. Hal ini menunjukkan ada indikasi kesalahan hasil pengecekan operator dan juga bagian quality sehingga produk tersebut dapat di katakan acceptable di internal perusahaan dan tetap dilanjutkan prosesnya namun setelah sampai kepada customer dinyatakan cacat/reject .

Sistem pengukuran adalah seluruh proses yang digunakan untuk mendapatkan suatu pengukuran yang terdiri dari alat ukur, standard, operasi, metode, fixtures, software, personil, lingkungan dan asumsi yang digunakan mengkuantifikasi unit pengukuran. Measurement atau pengukuran didefinisikan sebagai suatu ketetapan angka (atau nilai) terhadap suatu material yang menunjukan hubungan antara mereka terhadap sifat khususnya. Measurement System Analysis merupakan suatu analisa sistem pengukuran digunakan untuk mengetahui penyebab varian proses pengukuran agar variasi 
yang terjadi dalam proses dapat diantisipasi seminimal mungkin.

Penelitian tentang MSA pernah dilakukan oleh Sigit Budiantono, Sri Mumpuni Retnaningsih, dan Diaz Fitra Aksioma pada tahun 2016 di PT Jaykay Files Indonesia (Budiantono, 2016). Pada tahun 2013 Luh Made Pramitasari dari ITS juga melakukan penelitian yang menggunakan metode ini untuk proses oriented basis pada PT Alstom Power Esi (Pramitasari \& Mashuri, 2013). Metode yang sama juga digunakan oleh Anggrek Ayu Puspasari dan Sri Mumpuni Retnaningsih untuk menerapkan repeatability dan reproducibility pada produksi lampu (Puspasari \& Retnaningsih, 2013).

Tujuan dari penelitian ini adalah Untuk mengetahui penyebab pasti kesalahan hasil pengecekan bagian quality sehingga produk tersebut dapat di katakan acceptable di internal perusahaan, namun setelah sampai kepada customer dinyatakan cacat/reject. Dan Untuk mengetahui Seberapa besar nilai pengukuran MSA Gage R\&R pada produk base plate magazine.

\section{Landasan Teori}

Gage R\&R adalah perkiraan dari kombinasi dari repeatability dan reproducibility dan Dalam data sheet dan form report pengukuran repeatability dan reproducibility yang dijelaskan pada tabel 1., yang akan menyediakan metode analisis data dalam study pengukuran. Analisa dari variasi dan persentasi variasi akan diestimasi secara keseluruhan untuk menghasilkan total dari hasil pengukuran serta komponen repeatability, reproducibility dan variasi ukuran produk yang diukur (Down, Kerkstra, Cvetkovski, \& Benham, 2005).

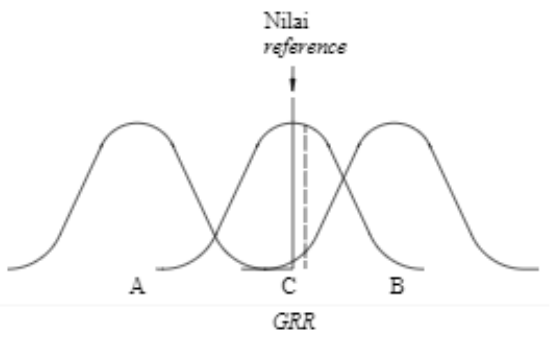

Gambar 1. Gage R\&R

(Budiantono, 2016)

Repeatability atau equipment variation ( $\mathrm{EV}$ atau $\sigma \mathrm{e}$ ) ditentukan dengan mengalikan kisaran rata-rata keseluruhan $(\overline{\bar{R}})$ dengan sebuah konstanta (K1), K1 tergantung pada jumlah percobaan yang digunakan dalam studi pengukuran yang dilakukan.

Sedangkan reproducibility atau appraiser variation (Av atau $\sigma 0$ ) ditentukan dengan mengalikan perbedaan rata-rata maksimum operator ( XDIFF) dengan sebuah konstanta (K2). Tergantung pada jumlah operator yang digunakan dalam study pengukuran. Sejak appraiser variation dikombinasikan dengan equipment variation, sehingga harus disesuaikan dengan mengurangi beberapa bagian equipment variation, dengan kombinasi tersebut maka untuk mencari appraiser variation (Av atau $\sigma 0$ ) adalah sebagai berikut:

$$
\mathrm{AV}=\sqrt{\left(\mathrm{XDIFF} \times \mathrm{K}_{2}\right)^{2}-\left\lceil\frac{(E V)^{2}}{(n r)}\right\rceil}
$$

Dimana $\mathrm{n}=$ jumlah part, $\mathrm{r}=$ jumlah uji coba, jika nilai yang didapatkan negatif dihitung dibawah akar kuadrat.

Pada penjelasan pada paragraf pertama dijelaskan bahwa terdapat data sheet dan form report yang akan mempermudah perhitungan dan pengukuran dalam pengambilan data, berikut bentuk dari data sheet dan form report tersebut.

Tabel 1. Data Sheet dan Form Report

\begin{tabular}{|c|c|c|c|c|c|c|c|c|c|c|c|c|}
\hline \multirow{2}{*}{ no } & \multirow{2}{*}{\begin{tabular}{|c|} 
operation/ \\
Trial \\
\end{tabular}} & \multicolumn{10}{|c|}{ PART } & \multirow{2}{*}{ average } \\
\hline & & 1 & 2 & 3 & 4 & 5 & 6 & 7 & 8 & 9 & 10 & \\
\hline 1 & A 1 & & & & & & & & & & & \\
\hline 2 & 2 & & & & & & & & & & & \\
\hline 3 & 3 & & & & & & & & & & & \\
\hline 4 & AVERAGE & & & & & & & & & & & $X_{a}=$ \\
\hline 5 & RANGE & & & & & & & & & & & $R_{a}=$ \\
\hline 6 & B 1 & & & & & & & & & & & \\
\hline 7 & 2 & & & & & & & & & & & \\
\hline 8 & 3 & & & & & & & & & & & \\
\hline 9 & AVERAGE & & & & & & & & & & & $X_{a}=$ \\
\hline 10 & RANGE & & & & & & & & & & & $\mathrm{Rb}=$ \\
\hline 11 & $\begin{array}{ll}\text { B } & 1 \\
\end{array}$ & & & & & & & & & & & \\
\hline 12 & 2 & & & & & & & & & & & \\
\hline 13 & 3 & & & & & & & & & & & \\
\hline 14 & AVERAGE & & & & & & & & & & & $X_{a}=$ \\
\hline 15 & RANGE & & & & & & & & & & & $R C=$ \\
\hline 16 & $\begin{array}{c}\text { PART } \\
\text { AVERAGE } \\
\end{array}$ & & & & & & & & & & & $R_{p}=$ \\
\hline 17 & $(\mathrm{Ra}=$ & $+R b=$ & & $+R c=$ & & )//\# & †umla & hope & rator=- & $1=$ & & $R$ \\
\hline 18 & ( Max Xbar = & & & - Min & & & $1=X_{D I}$ & & & & & \\
\hline 19 & $(R=$ & $x D 4^{*}=$ & & & $1=U($ & & & & & & & \\
\hline 20 & $(R=$ & $x 3^{*}=$ & & & $1=L C$ & & & & & & & \\
\hline
\end{tabular}

Sumber : Pengolahan Data

Pada tabel diatas D4* digunakan untuk ujicoba sebanyak 2 kali dan 2,58 digunakan apabila ujicoba yang digunakan sebanyak 3 kali, dan D3* adalah 0 UCL dan LCL merupakan batas maksimal dan minimal dari individu R's. Setelah proses pengambilan data pengisian pada tabel 2.1 terdapat beberapa rumus untuk mengetahui rincian dari data diatas yang disebut measurement unit analysis (Louka ${ }^{1}$ \& Besseris, 2011).

\section{Metode Penelitian}

Pengumpulan data yang diambil menggunakan data primer dan data sekunder, untuk data primer diambil langsung dari observasi di lapangan dan data sekunder diambil adalah 
data-data dari dokumen yang disimpan untuk menunjang data primer. Data yang diambil dalam penelitian ini merupakan data aktual yang diambil dilapangan dimana peneliti terlibat langsung didalamnya data inilah yang merupakan data primer dalam penelitian ini, dan dalam pelaksanaannya peneliti bekerjasama dengan 3 orang QC operator yang biasa mengecek produk base plate magazine kemudian untuk sample menggunakan $8 \mathrm{Pcs}$ produk base plate magazine yang diambil untuk pengiriman bulan agustus, dan banyaknya pengulangan dalam pengecekan adalah 3 kali. didalam penelitian ini alat yang dugunakan oleh operator adalah, high gauge. untuk ketelitian alat yang digunakan adalah 0.001 $\mathrm{mm}$.

Tabel 2. Data Pengukuran

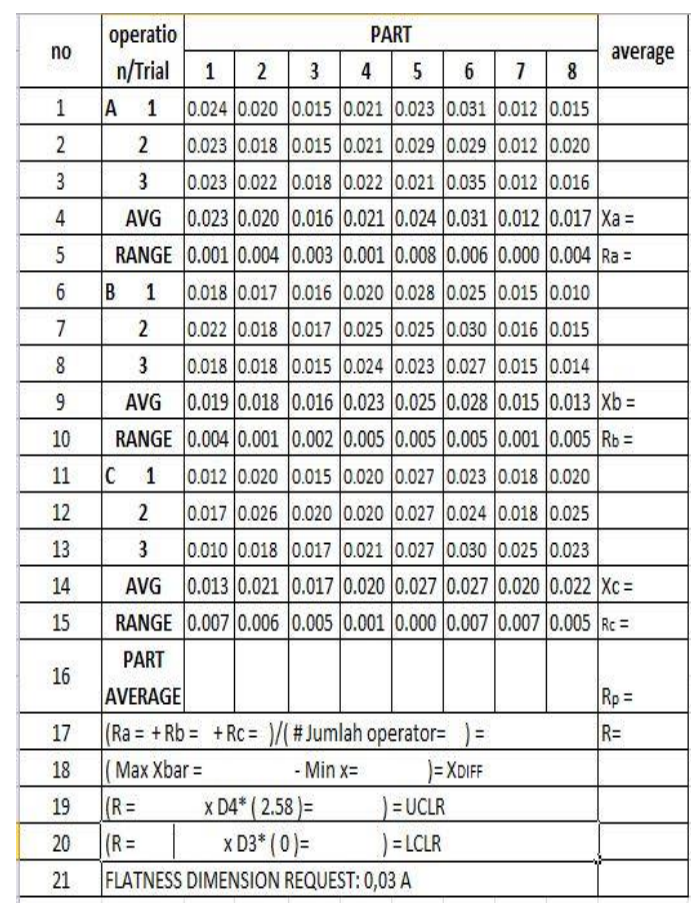

Sumber : Pengolahan Data

Setelah data dimasukan seperti tabel diatas maka data diolah data dengan measurement unit analysis dengan rumus sebagai berikut:

$\mathrm{EV}=\mathrm{R} \times \mathrm{K} 1$

$\mathrm{AV}=\sqrt{(\mathrm{XDIFF} \times \mathrm{K} 2)^{2}-\left\lceil\frac{(E V)^{2}}{(n r)}\right\rceil}$

$\mathrm{R} \& \mathrm{R}=\sqrt{\left(E V^{2}+A V^{2}\right)}$

$\mathrm{PV}=\mathrm{Rp} \times \mathrm{K} 3$

$\mathrm{TV}=\sqrt{\left(R \& R^{2}+P V^{2}\right)}$

Untuk mencari persentase metode MSA dilakukan penghitungan dengan percentage Measurement System Analysis dengan rumus sebagai berikut: (Knowles, Antony, \& Vickers, 2000)
$\% \mathrm{EV}=100(\mathrm{EV} / \mathrm{TV})$
$\% \mathrm{AV}=100(\mathrm{AV} / \mathrm{TV})$
$\% \mathrm{R} \& \mathrm{R}=100(\mathrm{R} \& \mathrm{R} / \mathrm{TV})$
$\% \mathrm{PV}=100(\mathrm{PV} / \mathrm{TV})$

Kriteria keberterimaan width error Ketentuan tersebut adalah sebagai berikut: (Kooshan, 2012)

1. \%GRR < 10\%: secara umum dianggap sebagai sistem pengukuran yang layak dipakai.

2. $10<\%$ GRR $<30$ : system pengukuran dapat dipakai dengan dasar kepentingan aplikasi, biaya alat pengukuran, biaya perbaikan dan sebagainya.

3. \%GRR > 30 : system pengukuran dianggap tidak layak digunakan. Diperlukan usahausaha untuk memperbaiki system pengukuran.

\section{Hasil Dan Pembahasan}

Untuk langkah awal dalam penelitian setelah semua data ditulis didalam tabel 4.1 diatas maka proses selanjutya peneliti mencari hasil dari perhitungan didalam tersebut, berikut hasil perhitugan dari tabel perhitungan diatas:

Tabel 3. Perhitungan MSA

\begin{tabular}{|c|c|c|c|c|c|c|c|c|c|c|}
\hline \multirow{2}{*}{ no } & \multirow{2}{*}{$\begin{array}{c}\text { operatio } \\
\text { n/Trial }\end{array}$} & \multicolumn{8}{|c|}{ PART } & \multirow{2}{*}{ average } \\
\hline & & 1 & 2 & 3 & 4 & 5 & 6 & 7 & 8 & \\
\hline 1 & A 1 & 0.024 & 0.020 & 0.015 & 0.021 & 0.023 & 0.031 & 0.012 & 0.015 & 0.019 \\
\hline 2 & 2 & 0.023 & 0.018 & 0.015 & 0.021 & 0.029 & 0.029 & 0.012 & 0.020 & 0.020 \\
\hline 3 & 3 & 0.023 & 0.022 & 0.018 & 0.022 & 0.021 & 0.035 & 0.012 & 0.016 & 0.020 \\
\hline 4 & AVG & 0.023 & 0.020 & 0.016 & 0.021 & 0.024 & 0.031 & 0.012 & 0.017 & $x_{a}=0.020$ \\
\hline 5 & RANGE & 0.001 & 0.004 & 0.003 & 0.001 & 0.008 & 0.006 & 0.000 & 0.004 & $R_{a}=0.0035$ \\
\hline 6 & B 1 & 0.018 & 0.017 & 0.016 & 0.020 & 0.028 & 0.025 & 0.015 & 0.010 & 0.019 \\
\hline 7 & 2 & 0.022 & 0.018 & 0.017 & 0.025 & 0.025 & 0.030 & 0.016 & 0.015 & 0.021 \\
\hline 8 & 3 & 0.018 & 0.018 & 0.015 & 0.024 & 0.023 & 0.027 & 0.015 & 0.014 & 0.019 \\
\hline 9 & AVG & 0.019 & 0.018 & 0.016 & 0.023 & 0.025 & 0.028 & 0.015 & 0.013 & $\mathrm{Xb}=0.020$ \\
\hline 10 & RANGE & 0.004 & 0.001 & 0.002 & 0.005 & 0.005 & 0.005 & 0.001 & 0.005 & $\mathrm{Rb}=0.0033$ \\
\hline 11 & C 1 & 0.012 & 0.020 & 0.015 & 0.020 & 0.027 & 0.023 & 0.018 & 0.020 & 0.020 \\
\hline 12 & 2 & 0.017 & 0.026 & 0.020 & 0.020 & 0.027 & 0.024 & 0.018 & 0.025 & 0.021 \\
\hline 13 & 3 & 0.010 & 0.018 & 0.017 & 0.021 & 0.027 & 0.030 & 0.025 & 0.023 & 0.022 \\
\hline 14 & AVG & 0.013 & 0.021 & 0.017 & 0.020 & 0.027 & 0.027 & 0.020 & 0.022 & $X_{C}=0.0 .02$ \\
\hline 15 & RANGE & 0.007 & 0.006 & 0.005 & 0.001 & 0.000 & 0.007 & 0.007 & 0.005 & $R C=0.0054$ \\
\hline 16 & $\begin{array}{c}\text { PART } \\
\text { AVERAGE }\end{array}$ & & 000 & 000 & .001 & 0.0014 & 40.0014 & 0.0008 & 80.0009 & $R_{p}=0.0006$ \\
\hline 17 & $(\mathrm{Ra}=0.00$ & $035+R b$ & $0=0.0 \mathrm{c}$ & $233+R$ & $R c=0.0$ & $054) /($ & (\# Jumla & lah ope & erator= & $R=0.0040$ \\
\hline 18 & ( Max Xba & $\mathrm{ar}=0 . \mathrm{C}$ & .021 & & $-\operatorname{Min} x$ & & .020 & & XDIFF & 0.001 \\
\hline 19 & $(R)=$ & 0.0040 & XD4 & $*^{*}(2.58$ & $58)=$ & & I $=U C L R$ & & & 0.0103 \\
\hline 20 & $R=$ & 0.0040 & & $\mathrm{D} 3^{*}(0$ & & & ) $=L C L R$ & & & 0 \\
\hline 21 & FLATNESS & SDIMEN & NSION & REQUES & EST: 0,0 & & & & & \\
\hline
\end{tabular}

Sumber : Pengolahan Data

Setelah data dimasukan seperti tabel diatas maka data diolah data dengan measurement unit analysis sebagai berikut:

Tabel 4. Measurement Unit Analysis \&\% Measurement System Analysis

\begin{tabular}{|c|c|}
\hline \multicolumn{1}{|c|}{ Measurement Unit Analysis } & $\begin{array}{c}\% \text { Measurement System } \\
\text { Analysis }\end{array}$ \\
\hline Repeatability-Equipment & $\% \mathrm{EV}=100(\mathrm{EV} / \mathrm{TV})$ \\
\hline
\end{tabular}




\begin{tabular}{|c|c|}
\hline $\begin{array}{l}\text { Variation }(\mathrm{EV}) \\
\mathrm{EV}=\mathrm{R} \times \mathrm{K} 1 \\
=0.0040 \times 3.05 \\
=0.0122\end{array}$ & $\begin{array}{l}\quad=100 \\
(0.0122 / 0.0093) \\
\quad=13.1 \%\end{array}$ \\
\hline $\begin{array}{l}\begin{array}{l}\text { Reproducibility }- \text { Appraiser } \\
\text { Variation }(\mathrm{AV})\end{array} \\
\mathrm{AV}=\sqrt{(\mathrm{XDIFF} \times \mathrm{K} 2)^{2}-\left[\frac{(\mathrm{EVV})^{2}}{(n r)}\right\rceil} \\
\mathrm{AV}=\sqrt{(0.001 \times 2.70)^{2}-\left[\frac{(0.0122)^{2}}{(13 \times 3)}\right\rceil} \\
\mathrm{AV}=0.0015\end{array}$ & $\begin{aligned} \% \mathrm{AV} & =100(\mathrm{AV} / \mathrm{TV}) \\
& =100 \\
(0.0015 / 0.0093) & \\
& =16.1 \%\end{aligned}$ \\
\hline 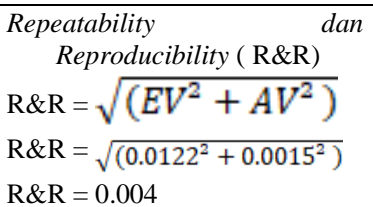 & $\begin{array}{c}\% \mathrm{R} \& \mathrm{R}=100 \\
(\mathrm{R} \& \mathrm{R} / \mathrm{TV}) \\
=100 \\
(0.004 / 0.0093) \\
=43.01 \%\end{array}$ \\
\hline $\begin{array}{l}\text { Part Variation }(\mathrm{PV}) \\
\mathrm{PV}=\mathrm{Rp} \times \mathrm{K} 3 \\
\mathrm{PV}=0.0004 \times \mathrm{K} 3 \\
\mathrm{PV}=0.004 \times 1.74 \\
\mathrm{PV}=0.006\end{array}$ & $\begin{aligned} \% \mathrm{PV} & =100(\mathrm{PV} / \mathrm{TV}) \\
& =100( \\
0.006 / 0.0093) & \\
& =64.51 \%\end{aligned}$ \\
\hline $\begin{array}{l}\text { Total Variation }(\mathrm{TV}) \\
\mathrm{TV}=\sqrt{\left(R \& R^{2}+P V^{2}\right)} \\
\mathrm{TV}=\sqrt{\left(0.004^{2}+0.006^{2}\right)} \\
\mathrm{TV}=0.0093\end{array}$ & \\
\hline
\end{tabular}

Sumber : Pengolahan Data

Berdasarkan data tabel dan perhitungan pada tabel diatas. Hasil yang didapatkan pada Gage $R \& R$ cukup besar yaitu $43.1 \%$. Dengan nilai 43.1\% maka dapat dinyatakan bahwa sistem pengukuran yang dilakukan pada produk base plate magazine selama ini tidak layak digunakan (Dewi, 2013) dan perlu diadakan usaha perbaikan untuk memperbaiki sistem.pengukuran. Dengan nilai persentase pada repeatability adalah $13.1 \%$ sedangkan untuk nilai reproducibility adalah $16.1 \%$. dapat diketahui system mana yang harus diperbaiki terlebih dahulu, dalam kasus ini yang harus diperbaiki terlebih dahulu adalah reproducibility dikarenakan nilai persentase nya lebih besar daripada repeatability, Untuk memastikan nilai reproducibility tersebut peneliti melakukan wawancara kepada operator yang melakukan pengecekan produk tersebut.

\section{Kesimpulan}

Setelah dilakukan pengumpulan data dan pengolahan data dengan metode MSA gage $\mathrm{R} \& \mathrm{R}$, penyebab utama masalah pengecekan pada produk base plate magazine adalah reproducibility dimana nilai reproducibility ini lebih besar dari pada nilai repeatability dan hal yang berkenaan dengan reproducibility ini adalah masalah training, kalibrasi, dan kelangkapan alat ukur.

Berdasarkan pengolahan dengan metode MSA gage R\&R bahwa nilai yang didapat untuk perhitungan gage R\&R adalah sebesar 0.0004 dengan persentase $43.01 \%$ yang mana persentase tersebut dapat dikatakan bahwa system pengukuran yang dilakukan tidak layak digunakan karna standar layaknya suatu system pengukuran digunakan adalah dibawah $30 \%$. Dan untuk persentase repeatability adalah $13.1 \%$ dan reproducibility adalah $16.1 \%$

\section{Daftar Referensi}

Budiantono, S. (2016). Meassurement System Analysis Repeatability Dan Reproducibility (Gauge R\&R) Pada Alat Vickers Hardness Tester Di Pt Jaykay Files Indonesia. Institut Teknologi Sepuluh Nopember Surabaya.

Dewi, N. S. (2013). Measurement System Analysis Repeatability dan Reproducibility (Gauge R\&R) Studi Kasus: PT. Gaya Motor (Astra Group). Surabaya: Jurusan Statistika ITS.

Down, M. H., Kerkstra, T., Cvetkovski, P., \& Benham, D. R. (2005). Statistical Process Control (SPC) Reference Manual. AIAG Southfield, MI.

Knowles, G., Antony, J., \& Vickers, G. (2000). A practical methodology for analysing and improving the measurement system. Quality Assurance, 8(2), 59-75.

Kooshan, F. (2012). Implementation of Measurement System Analysis System (MSA): In the Piston Ring Company" Case Study. Int. J. Sci. Technol.

Louka1 ${ }^{1}$, G. A., \& Besseris, G. J. (2011). Gauge $\mathrm{R} \& \mathrm{R}$ for an optical micrometer industrial type machine. Center for Quality.

Pramitasari, L. M., \& Mashuri, M. (2013). PENERAPAN MEASUREMENT SYSTEM ANALYSIS UNIVARIAT. Digilib ITS, 1-6.

Puspasari, A. A., \& Retnaningsih, S. M. (2013). Penerapan repeatability and reproducibility (msa gauge r\&r) pada produk lampu di pt.”x". Digilib ITS, 1-7. 